http://jmscr.igmpublication.org/home/

ISSN (e)-2347-176x ISSN (p) 2455-0450

crossref DOI: https://dx.doi.org/10.18535/jmscr/v7i8.97

Journal Of Medical Science And Clinical Research

\title{
To Study the effect of altitude, route of administration and age on pain response to vaccination at birth
}

\author{
Authors \\ Dr Pratima Thakur ${ }^{1 *}$, Dr Pancham Kumar ${ }^{2}$, Dr Rakesh Sharma ${ }^{2}$, Dr Banita Negi ${ }^{3}$ \\ ${ }^{1}$ Department of Paediatrics SLBSGMCH Nerchowk \\ ${ }^{2}$ Department of Paediatrics Indira Gandhi Medical College, Shimla, \\ ${ }^{3}$ Deprtment of Paediatrics RPGMC Tanda \\ *Corresponding Author \\ Dr Pratima Thakur \\ Senior Resident, Department of paediatrics SLBSGMCH, Nerchowk, Mandi, HP., India
}

\begin{abstract}
Background and Aims: Neonatal pain has been under diagnosed and undertreated since forever and misconceptions regarding neonatal pain is the main reason behind it. Healthy neonates usually experience pain during the first week of life due to several medical procedures such as procedures such as blood sampling, immunization, vitamin K injection, or circumcision. Vaccination is one of the most painful procedures in infants and is the most common source of pain in childhood.

Methods: We observed 400 neonates receiving routine dose of BCG and Hepatitis B vaccine given at birth. Pain was assessed on NIPS scale 30 second after first injection and 30 seconds after second injection. The two injections were given 2 minutes apart.

Results: On comparing the combined score for Hepatitis B and BCG in neonates with age < 24 hours was $12.35 \pm 5.07$ and in neonates of $>24$ hours mean score after vaccination was 12.84 \pm 4.63 . The $p$ value was 0.189 , which was not significant. The combined mean nips score after Hepatitis B plus BCG injection in neontes residing at altitudes of $<999 m, 1000-1999 m,>2000 m$ was $12.35 \pm 4.78,12.58 \pm 4.74,12.61 \pm 5.18$ respectively, with a $p$ value of 0.968.Pain during the intramuscular route of injection was significantly higher than intradermal with a mean NIPS score of $8.47 \pm 3.09$ vs $3.8 \pm 2.45$ (table 4 ) and $P$ value of $<0.0001$, indicating that intramuscular route of vaccination is more painful than intradermal route.

Conclusion: there was no significant effect age in hours and altitude on pain perceived due to vaccination given at birth in the neontes. Pain perceived was more on intermuscular route of vaccination than on intradermal route.

Keywords: Vaccination, Neonatal Infant Pain Scale Score, Neonate, Pain, BCG Vaccine, Hepatitis B Vaccine, altitude, age, route of administration.
\end{abstract}

\section{Introduction}

Healthy neonates usually experience pain during the first week of life due to several medical procedures such as procedures such as blood sampling, immunization, vitamin $\mathrm{K}$ injection, or circumcision. Vaccination is one of the most painful procedures in infants and is the most common source of pain in childhood $^{(1)}$.
Vaccination are considered as the safest and most effective way to prevent serious illness and death $^{(2)}$. In fact, it has been observed that vaccination prevent approximately 2.5 million death every year, globally ${ }^{(3)}$. Pain during vaccination is a source of distress to both the neontes as well as their parents. It may have immediate and long-term effects on the infants. Its 
immediate effects include syncope, ${ }^{(4)}$ fear, irritability, sleep disorder, and a reduction in nutrition. Its short-term effects include a delay in wound healing, a change in immunity system function, endocrine and biochemical changes, increased cortisol and catecholamine release, increased glucagon, growth hormone, rennin, aldosterone, and antidiuretic hormones, and decreased insulin secretion. They also include physiological changes such as apnea, bradycardia, skin color changes, sweating palms, tachycardia, hypertension, increased respiration rate and muscular tonicity, increased intracranial pressure and oxygen intake, and behavioural changes including fretting, crying, etc. ${ }^{(5,6)}$ Long-term effects of vaccination are delayed development and having different responses to similar painful experiences, long-term effects on neurotransmitters and endocrinal systems, as well as long-term complications on brain development and fear of future injections ${ }^{(7,8)}$.

The purpose of this study is to help to understand the factors that affect the response to pain in neontes. Thus, better understanding of the factors effecting acute response to pain will help in devising methods to reduce pain in neontes. Less painful methods for vaccination will reduce the stress among the children and their parents. Intense anxiety experienced by parents and their children regarding vaccination may result in nonadherence to the recommended vaccination schedule. Thus, devising a less painful and less stressful route and method for vaccine administration may help in improving the compliance to vaccination ${ }^{(9)}$.

\section{Aims and Objective}

To study the effect of altitude, age in hours and mode of administration of vaccine on acute pain response to vaccination given at birth

\section{Material and Methods}

The study was conducted at Kamla Nehru State Hospital for Mother and child, a unit of Department of Paediatrics at Indira Gandhi medical College, Shimla. It was a hospital based observational cross-section study.

\section{Inclusion Criteria}

1. All full-term healthy neonates receiving BCG and Hepatitis B vaccination at birth.

2. Parents consenting to include their newborns in the study.

\section{Exclusion Criteria}

1. Sick newborns and newborn on any supportive care

2. Preterm and IUGR newborn

3. Newborns with major congenital anomalies With confidence limit of $95 \%$ and absolute error of $10 \%$ the sample size calculated was 384 . So, 400 neonates meeting our requisite criteria were included in the study. The demographic profile of the all the cases was recorded as per a structured case recording format Table 1. All the infants were dry at the time of procedure. The newborns were laid on the radiant warmer during entire procedure so as to observe pain score correctly. Vaccination was given to the neonate at the Brazelton state 3-4 of arousal. Neonates were breast fed half to one hour prior to vaccination. Same examination room with same radiant warmer and same surroundings was used for all the neonates in a thermo neutral temperature with NIPS of zero prior to vaccination. NIPS score was used to assess the pain in our study. To maintain uniformity the same size needles of same make were used. Vaccination was given by the same health worker to minimise subjective variation. She was not informed about the outcomes of the procedure and was be blinded to the purpose and hypothesis of the study. Standard immunization procedures were used. $0.1 \mathrm{ml}$ of BCG vaccine was administered intradermally ${ }^{(10)}$ at the convex aspect of left shoulder using a tuberculin syringe with $0.45 \mathrm{x} 13 \mathrm{~mm}$ needle ${ }^{(11)}$. $0.5 \mathrm{ml}$ of Hepatitis $\mathrm{B}$ vaccine was administered intramuscularly ${ }^{(10)}$ at the anterolateral aspect of thigh using $0.60 \times 25 \mathrm{~mm}$ needle ${ }^{(11)}$. Pain was assessed using NIPS scale after 30 second of first injection and 30 seconds after second injections. The data analysis was done using Statistical Package for Social Sciences 
(SPSS) version 21.0. Statistical analysis of the data was done to find the difference in pain intensity on NIPS scale. Categorical variables were presented in number and percentage (\%) and continuous variables were presented as mean \pm SD and median. Normality of data was tested by Kolmogorov-Smirnov test. If the normality was rejected then non parametric test was used. Qualitative variables were correlated using ChiSquare test /Fisher's exact test. A p value of $<0.05$ was considered statistically significant.

\section{Results}

In our study total of 400 healthy term neontes fulfilling the inclusion criteria were enrolled, who received the routine dose of BCG and Hepatitis B vaccine at birth. Of all the neontes taken for the study, 243 neontes were vaccinated at age less than 24 hours and 157 neontes were vaccinated at age more than 24 hours. On comparing the combined score for Hepatitis B and BCG in neonates with age $<24$ hours was $12.35 \pm 5.07$ and in neonates of >24hours mean score after vaccination was $12.84 \pm 4.63$. The $p$ value was 0.189 (Table 2). The $\mathrm{p}$ value obtained is not significant. Thus, age in hours at the time of vaccination does not affect the pain experienced by the neonates.

Altitude: there were 83 neontes belonging to altitude $<999$ m, 175 belonging to altitude 1000$1999 \mathrm{~m}$ and 145 belonging to altitude of more than $2000 \mathrm{~m}$. The combined mean nips score after Hepatitis B plus BCG injection in neontes residing at altitudes of $<999 \mathrm{~m}, 1000-1999 \mathrm{~m},>2000 \mathrm{~m}$ was $12.35 \pm 4.78,12.58 \pm 4.74,12.61 \pm 5.18$ respectively, with a $\mathrm{p}$ value of 0.968 (Table 3 ). The $\mathrm{p}$ value is not significant. Thus, the altitudes to which the neonates belonged did not have an effect on the pain perceived by them.

Route of vaccination: Pain during the intramuscular route of injection was significantly higher than intradermal with a mean NIPS score of $8.47 \pm 3.09$ vs 3.8 \pm 2.45 (table 4) and $P$ value of $<0.0001$.

Table 1: Demographic profile of the new borns enrolled

\begin{tabular}{|l|c|c|c|}
\hline Characteristic & & Frequency & Percentage \\
\hline \multirow{3}{*}{ Gender } & Male & 173 & $43.25 \%$ \\
\cline { 2 - 4 } & Female & 227 & $56.75 \%$ \\
\hline \multirow{3}{*}{ Birth weight } & $<3 \mathrm{~kg}$ & 245 & 61.255 \\
\cline { 2 - 4 } & $\geq 3 \mathrm{~kg}$ & 155 & $38.75 \%$ \\
\hline \multirow{3}{*}{ Age in hours } & $<24$ hours & 243 & $60.75 \%$ \\
\cline { 2 - 4 } & $>24$ hours & 157 & $39,25 \%$ \\
\cline { 2 - 4 } & $<999 \mathrm{~m}$ & 83 & $20.75 \%$ \\
\cline { 2 - 4 } & $1000-1999 \mathrm{~m}$ & 175 & $43.75 \%$ \\
\cline { 2 - 4 } & $>2000 \mathrm{~m}$ & 142 & $35.5 \%$ \\
\hline
\end{tabular}

Table 2: NIPS with Respect to Altitude

\begin{tabular}{|l|c|c|c|c|c|c|}
\hline \multicolumn{1}{|c|}{ Altitude } & Sample size & Mean $+\_$SD & Median & Min- max & Inter quartile range & P value \\
\hline$<999 \mathrm{~m}$ & 83 & $12.35+\_4.78$ & 12 & $2-23$ & $9-16$ & \multirow{2}{*}{0.968} \\
\cline { 1 - 6 } $1000-1999 \mathrm{~m}$ & 175 & $12.58+\_4.74$ & 12 & $3-27$ & $9.25-15$ & \\
\hline$>2000 \mathrm{~m}$ & 142 & $12.61+-5.18$ & 12 & $2-28$ & $9-17$ & \\
\hline
\end{tabular}

Table 3: NIPS with Respect to Age

\begin{tabular}{|l|c|c|c|c|c|}
\hline Age in Hours & Sample size & Mean+_SD & Median & Min __max & P value \\
\hline$<24$ hours & 243 & $12.35+\_5.07$ & 12 & 14 & \\
\cline { 1 - 5 }$>24$ hours & 157 & $12.84+\_4.63$ & 13 & 14 & 0.189 \\
\hline
\end{tabular}

Table 4: NIPS after BCG and Hepatitis B

\begin{tabular}{|l|c|c|c|c|}
\hline & Sample size & Mean +_SD & Median & P Value \\
\hline BCG & 400 & $3.8+\_2.45$ & 3 & \multirow{2}{*}{$<0.0001$} \\
\hline Hepatitis B & 400 & $8.74+\_3.09$ & 8 & $<0$ \\
\hline
\end{tabular}




\section{Discussion}

This study conducted at Kamla Nehru State Hospital of Mother And Child, Branch of Indra Gandhi Medical College, Shimla describes the effect of age in hours, altitude and mode of administration of vaccine on acute pain response vaccination given at birth. When the pain response to vaccination was compared in the neontes hailing from different altitudes, the NIPS score was $12.35 \pm 4.78,12.58 \pm 4.74,12.61 \pm 5.18$ in neontes belonging to altitudes $<999 \mathrm{~m}, 1000$ $1999 \mathrm{~m}$ and $>2000 \mathrm{~m}$ respectively. The $\mathrm{p}$ value was 0.968 , which was not significant. The NIPS score for the infants at the end of vaccination procedure with age <24hours at the time of vaccination was 12.35 \pm 5.07 , whereas the NIPS score for those with age $>24$ hours the time of vaccination was $12.84 \pm 4.62$, with $\mathrm{p}$ value of 0.189 , which was not significant. Thus, pain due to vaccination was not affected by the age in hours of life at which the neonates received the vaccination. Our findings were in collaboration with Pragya Pathak and Raman Kalia et al., ${ }^{(12)}$ who studied the "Effect of Needle Gauge on Perception of Pain Intensity Among Infants Receiving D.P.T and concluded that there is no significant difference in behavioural response to pain among infants up to 24 weeks age.

All the infants are given BCG vaccine and Hepatitis B vaccine according to immunisation program. Of the two vaccines, BCG is given by intradermal route and Hepatitis B is given by intramuscular route. Also, the NIPS score after receiving $B C G$ was $3.38 \pm 2.01$ and after Hepatitis $B$ vaccine $7.16 \pm 2.23$, with a $p$ value of $<0.0001$ which is statistically significant. Thus, the pain experienced by the neontes was less on BCG vaccine compared to Hepatitis B vaccine. Since BCG is given by intradermal route and Hepatitis $\mathrm{B}$ is given by intramuscular route, it may be concluded that intradermal route is less painful than intramuscular route of vaccination. The difference to the pain perceived by the neonates in two groups may be due to the fact that the route of administration of the two vaccines is different.
The difference may also be attributed to the fact that composition of the two vaccines is different and the needle used for the two vaccines is of different calibre. Our findings were in concordance with Minoo Sharma et $\mathbf{a l}^{(13)}$ who suggested that pain was more in intramuscular route as compared to intradermal route in neontes. Also, our findings are in agreement with evacignacco et $\mathbf{a l}^{(14)}$, who did multi centric study from four European neonatal intensive care units, intensity of pain for 27 common neonatal procedures was calculated using visual analogue scale and found that range of pain intensity was more for intramuscular as compared to heel prick. Thus, intramuscular route of injection is more painful procedure than heel prick method. Although, the pain assessment scale used by them is different so the results of their study may not be comparable to ours.

\section{Conclusion}

There was no effect of age in hours, altitude on pain perceived due to vaccination in the neontes. Hepatitis was found more painful then BCG indicating that intermuscular route of vaccination is more painful then intradermal route.

\section{Limitations:}

In our study only intramuscular and intradermal routes of vaccination were studied. Other routes like subcutaneous and intravenous and intradermal routes could not be studied. So, there is a need to do further extensive studies in this field for better understanding.

\section{Source of support: nil}

\section{References}

1. Schechter NL, Zempsky WT, Cohen LL, mcgrath PJ, mcmurtry CM, Bright NS. Pain reduction during pediatric immunizations: evidence-based review and recommendations. Pediatrics. 2007; 119:e1184-98. 
2. World health organisation. World health assembly endorses new plan to increase global access to vaccine [press release]. Geneva: world health organisation; [May25, 2014]. Available from; hptt://ww.who.int/immunisation/newsroo m/press/who_endorses_gvap/en.Accessed July14, 2014.

3. World Health Organization. World health assembly endorses new plan to increase global access to vaccines [press release]. Geneva: World Health Organization; [May 25, 2012].

4. Cohen LL, Maclaren JE, Demore M, Fortson B, Friedman A, Lim CS, et al. A randomized controlled trial of vapocoolant for pediatric immunization distress relief. Clin J Pain. 2009;25:490-4

5. Clifford Gevirtz MD, MPH, Anne Haddad. Topics in Pain Management Current Concepts and Treatment Strategies. Pain Management. 2008;23:1-12.

6. Bilgen H, Ozek E, Cebeci D, Ors R. Comparison of sucrose, expressed breast milk, and breastfeeding on the neonatal response to heal prick. J Pain. 2001;2:3015.

7. Ramponi D. Reducing pain in pediatric procedures in the emergency department. J Emerg Dep. 2009;35:379-82.

8. Harrison D. Oral sucrose for pain management in the paediatric emergency department; A review. Australas Emerg Nurs J. 2008;11:72-9.

9. Jay $\mathrm{S}$ Invasive medical procedures: psychological intervention and assessment. Routh Ded. Handbook of paediatric psychology New York, NY Guilford Press 1998;410- 425.

10. Indian Academy of Paediatrics Committee on Immunization (IAPCOI). Consensus recommendations on immunization, 2008. Indian Pediatr.2008 Aug; 45(8) :635-48.
11. Centres for disease control and prevention; Pink book; vaccine administration 2015;6;79 - 106.

12. Pathak P, Kalia R, Bharti B.Effect of needle gauge on perception of pain intensity among infants receiving D.P.T.vaccination. Nursing and Midwifery Research Journal 2007; 3(4):172-78.

13. Sharma M, Bhardwaj P, Singh B, Ahluwalia K. Assessment of pain intensity and its persistence following common needle prick procedures in newborns. Int $\mathbf{J}$ Clin Exp Physiol2014;1:226-8

14. Cignacco E, Hamers JP, Stoffel L, van Lingen RA, Schütz N, Müller R, et al. Routine procedures in nicus: Factors influencing pain assessment and ranking by pain intensity. Swiss Med Wkly2008;138:484-91. 